\title{
Correction to: Differences in pyroptosis of recent thymic emigrants CD4 + T Lymphocytes in ART-treated HIV-positive patients are influenced by sex
}

José Leandro Andrade-Santos ${ }^{1,2} \cdot$ Wlisses Henrique Veloso Carvalho-Silva ${ }^{2} \cdot$ Fabrício Oliveira Souto $^{2}$. Sergio Crovella ${ }^{1,2} \cdot$ Rafael Lima Guimarães ${ }^{1,2}$

Published online: 24 February 2021

(c) Springer-Verlag GmbH Germany, part of Springer Nature 2021

\section{Correction to: Clinical Rheumatology}

https://doi.org/10.1007/s00251-020-01202-5

The legend that represents Male and Female in the Fig. 1b image of the original published version of the above article was cut off. The original article has been corrected.

Publisher's Note Springer Nature remains neutral with regard to jurisdictional claims in published maps and institutional affiliations.

The original article can be found online at https://doi.org/10.1007/ s00251-020-01202-5

José Leandro Andrade-Santos

jlandrades19@gmail.com

1 Department of Genetics, Federal University of Pernambuco

UFPE, Recife, Pernambuco, Brazil

2 Laboratory of Immunopathology Keizo Asami

(LIKA), Federal University of Pernambuco UFPE,

Recife, Pernambuco 50670-901, Brazil 